\title{
Microsurgical and Endoscopic Anatomy of the Cavernous Sinus
}

\section{Anatomia microcirurgica e endoscópica do seio cavernoso}

\author{
Gustavo Rassier Isolan ${ }^{1,2(0)}$ Francisco Luiz Souza Braga ${ }^{1,2}$ Alvaro Campero ${ }^{30}$ José Alberto Landeiro ${ }^{40}$ \\ Ricardo Marques Lopes de Araújo ${ }^{1,2}$ Pablo Adjer $^{5}$ Gabriel Reis Sakaya ${ }^{6}$ Nícollas Nunes Rabelo6(0) \\ Josué da Silva Brito ${ }^{7(1)}$ Manoel Jacobsen Teixeira6(i) Eberval Gadelha Figueiredo ${ }^{6(1)}$
}

\footnotetext{
1 Department of Neurosurgery, The Center for Advanced Neurology and Neurosurgery (CEANNE Brazil), Brazil

2 Universidade Federal do Rio Grande do Sul, Porto Alegre, RS, Brazil

${ }^{3}$ Neurosurgery Service, Hospital Padilla, Tucumán, Argentina

${ }^{4}$ Department of Neurosurgery. Hospital da Força Aérea do Galeão, Rio

de Janeiro, RJ, Brazil

5 Neurosurgery Service, Hospital Italiano de Buenos Aires, Buenos

Aires, Argentina

${ }^{6}$ Department of Neurosurgery, Universidade de São Paulo, São Paulo,

SP, Brazil

${ }^{7}$ Department of Neurosurgery, Centro Universitário Atenas,

Paracatu, MG, Brazil
}

Arq Bras Neurocir 2020;39(2):83-94.

\author{
Address for correspondence Eberval Gadelha Figueiredo, MD, Phd \\ Neurosurgery Department, Universidade de São Paulo, Rua Eneas \\ Aguiar, 255, São Paulo, 05403-010, Brazil \\ (e-mail: ebgadelha@yahoo.com).
}

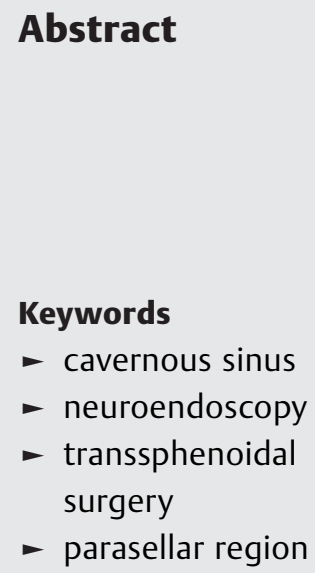

Resumo
Objective To describe the endoscopic and microsurgical anatomy of the cavernous sinus (CS) with focus on the surgical landmarks in microsurgical anatomy.

Materials and methods Ten formalin-fixed central skull base specimens (20 CSs) with silicone-injected carotid arteries were examined through an extended endoscopic transsphenoidal approach. Fifteen formalin-fixed heads were dissected to simulate the surgical position in CS approaches.

Results Endoscopic access enables identification of the anterior and posterior surgical corridors. Structures within the CS and on its lateral wall could be visualized and studied, but none of the triangular areas relevant to the transcranial microsurgical anatomy were fully visible through the endoscopic approach.

Conclusion The endoscopic approach to the CS is an important surgical technique for the treatment of pathological conditions that affect this region. Correlating endoscopic findings with the conventional (transcranial) microsurgical anatomy is a useful way of applying the established knowledge into a more recent operative technique. Endoscope can provide access to the CS and to the structures it harbors.

Objetivo O presente estudo objetiva descrever a anatomia endoscópica e microcirúrgica do seio cavernoso com foco nos marcos cirúrgicos da anatomia microcirúrgica. Materiais e métodos Foram avaliados 10 espécimes da base do crânio central fixados em formalina (20 seios cavernosos) com artérias carótidas injetadas com silicone através de abordagem transesfenoidal endoscópica estendida. Quinze cabeças fixadas em formalina foram dissecadas para simular a posição cirúrgica nas abordagens dos seios cavernosos. received

December 14, 2019

accepted

February 18, 2020
DOI https://doi.org/

10.1055/s-0040-1709740. ISSN 0103-5355.
Copyright $\odot 2020$ by Thieme Revinter

Publicações Ltda, Rio de Janeiro, Brazil
License terms

(ㄷ) (i) $\ominus$ (5) 


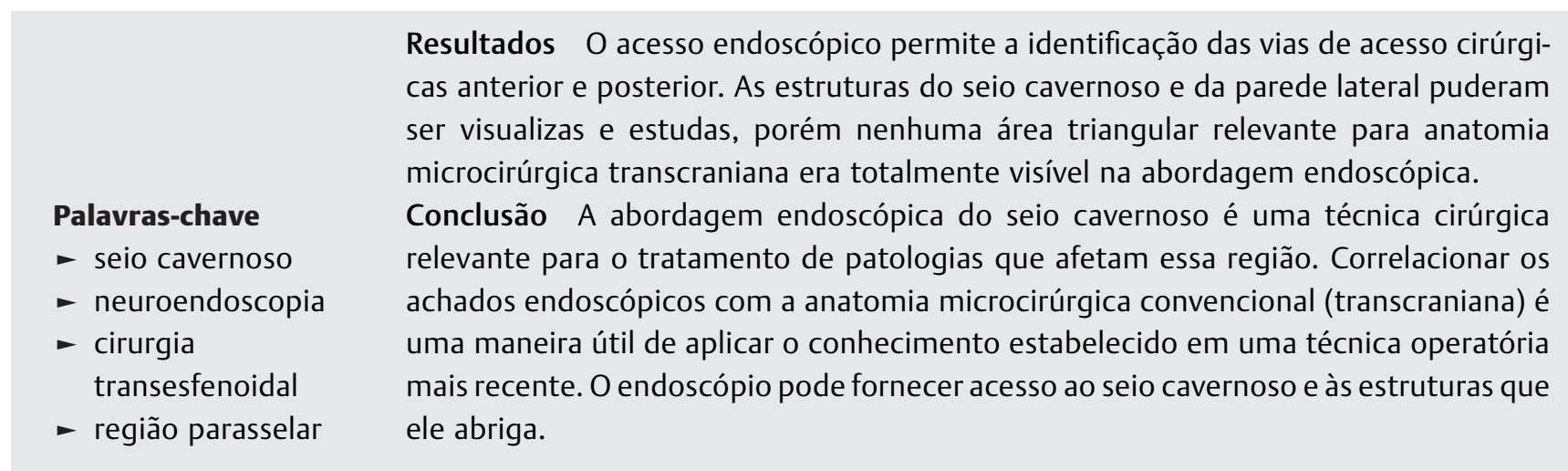

\section{Introduction}

The cavernous sinuses (CSs) are vascular structures located on each side of the sellar region that have a unique meningeal lining and harbor essential vascular and neural elements. The complex anatomical relationship between these structures, as well as their difficult-to-reach location, mean that surgical procedures involving the CS are highly challenging. ${ }^{1}$ The delicate anatomical structures of the area, which initially appear minute when the scope first enters the sphenoidal sinus, become greatly magnified as the instrument is advanced toward the area of interest.

This possibility of expanding the field of view into the anterior portion of the CS has come to allow resection of tumor lesions arising in or encroaching upon this area, as reported recently by some authors. ${ }^{2-8}$

The purpose of the present study is to describe the microsurgical and endoscopic anatomy of the CS, as well as to compare the visualization of the surgical triangles through both views.

\section{Materials and Methods}

Fifteen formalin-fixed heads were dissected at the microsurgical laboratory of the University of Florida to simulate the cavernous sinus surgery by one of the authors (Campero A).

Ten formalin-fixed central skull base specimens (20 CSs), with silicone-injected carotid arteries, were used for simulated endoscopic surgery at the microsurgery laboratory of the Hospital da Força Aérea do Galeão (HFAG, in the Portuguese acronym). These dissections were performed by two of the authors (Isolan G. R and Braga F. L. S.). All of the specimens included the posterior portion of the nasal cavity, through which the scopes were inserted. Two rigid, 18-cm, 4-mm endoscopes with 0-degree and 30-degree lenses (Karl Storz $\mathrm{GmbH}$ and co., Tuttlingen, Germany) were used. Images were displayed on a 20-inch monitor and sent to a Pinnacle video capture device (Pinnacle Systems, Mountain View, CA, USA) for storage and later editing in the Pinnacle Studio 12 software package (Pinnacle Systems, Mountain View, CA, USA). The internal anatomy of the sphenoidal sinus cavity was examined to relate it to the underlying neural and vascular structures.

The transillumination technique was employed by shining a light source on the lateral wall of the CS to cast a shadow of the parasellar structures as seen through the scope placed within the sphenoidal sinus, improving on the concept of "see-through, $\mathrm{x}$-ray type knowledge." This technique makes it possible for the surgeon to pinpoint the location of structures that do not contribute to the relief of the internal wall of the sphenoidal sinus.

\section{Results}

\section{Microsurgical Anatomy}

\section{Osseous Relationships}

The CS is bounded anteriorly, medially, and inferiorly by the sphenoid bone. The lesser wing of the sphenoid is bounded medially by the anterior clinoid process, which may sometimes be pneumatized as an extension of the sphenoidal sinus. The posterior clinoid process is located at the posterior portion of the roof of the cavernous sinus, in the superior and lateral aspects of the dorsum sella. The optic strut forms the anterior third of the floor of the clinoidal triangle, separating the optic canal and the superior orbital fissure. The foramen rotundum, ovale, and spinosum are situated in the middle cranial fossa and transmit the maxillary nerve, the mandibular nerve, and the middle meningeal artery, respectively (-Fig. 1). ${ }^{9,10}$

The tentorium attaches to the anterior and posterior clinoid processes and to the petrous apex, forming three dural folds: the anterior petroclinoid fold, which extends from the petrous apex to the anterior clinoid process; the posterior petroclinoid fold, which extends from the petrous apex to the posterior clinoid process; and the interclinoid fold, which is situated between the anterior and posterior clinoid processes.

These three folds delimit the oculomotor triangle, which forms the posterior portion of the roof of the CS. This portion of dura delimits the diaphragm sellae medially and blends with the dura of the middle fossa laterally. The medial extension of the dura to the anterior clinoid process forms the falciform ligament, which corresponds to the initial, nonosseous portion of the roof of the optic canal. The dura that lines the ascending vertical part of the ICA is known as

\section{Dural Relationships}




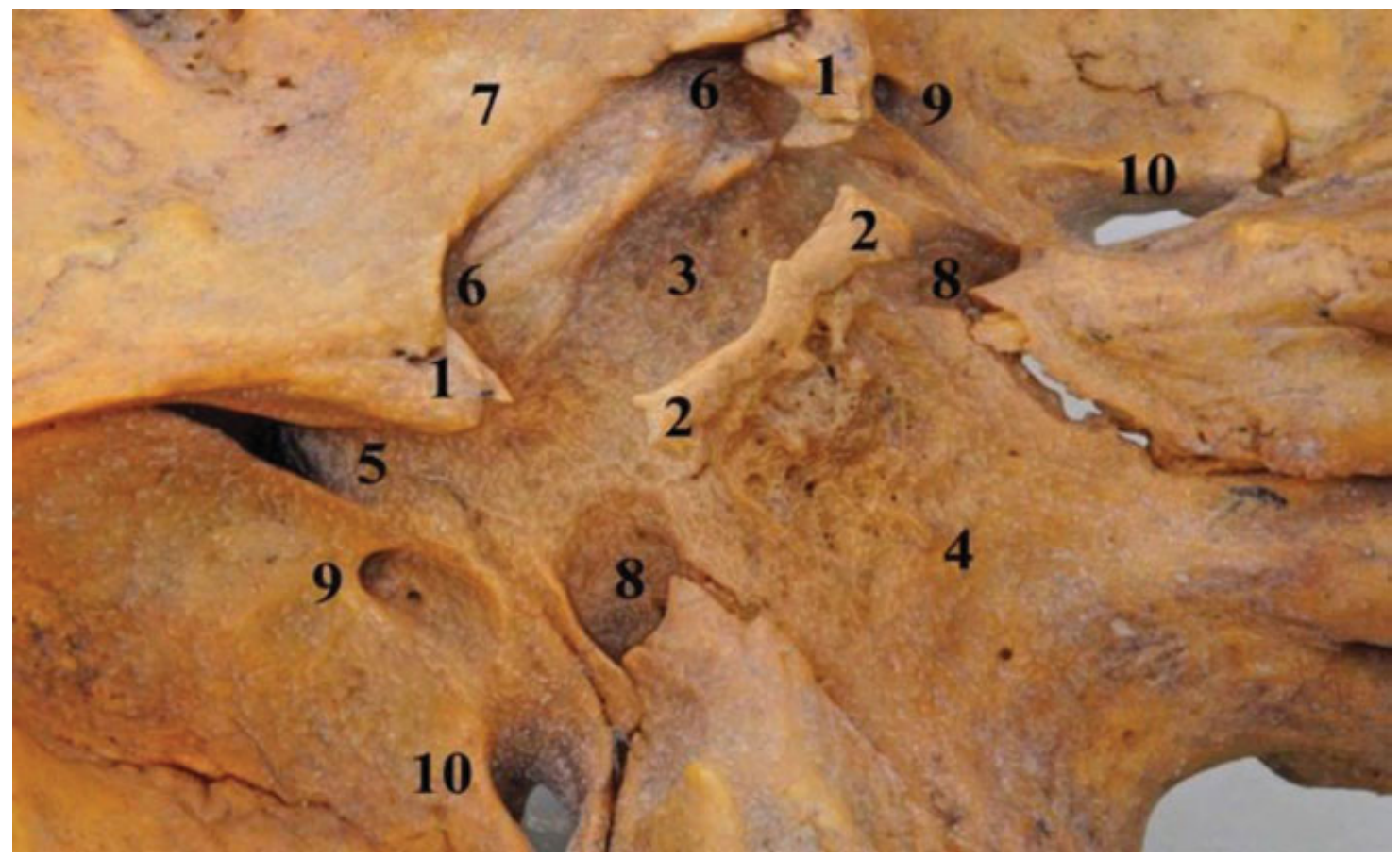

Fig. 1 Osseous relationship. Sellar and parassellar regions in oblique superior view. 1: Anterior clinoid process, 2: Posterior clinoid process, 3: Sellae, 4: Clivus, 5: Superior orbital fissure, 6: Optic canal, 7: Planun esphenoidale, 8: Carotid canal, 9: Foramen rotundum, 10: Foramen ovale.

the distal dural ring. The lateral wall of the CS is bound by two dural layers, a meningeal layer and an endosteal layer, whereas the medial sinus wall has only one layer of meningeal dura.

\section{Arterial Relationships: Internal Carotid Artery}

The internal carotid artery (ICA) enters the cranial cavity through the carotid canal and ends laterally to the optic chiasm, near the pituitary, where it divides into two terminal branches, the anterior cerebral artery and the middle cerebral artery. Over the length of its course, the ICA can be subdivided into four portions: ${ }^{11,12} \mathrm{C} 1$ (cervical), C2 (petrous), C3 (cavernous) and C4 (supraclinoid or cerebral) (-Fig. 2). The carotid artery also has a subclinoid portion, which is located between the proximal and distal dural rings and is covered by the anterior clinoid process ( $\mathbf{- F i g . ~ 3 ) . T h i s ~ a r t e r i a l ~ s e g m e n t ~ f o r m s ~}$ the middle portion of the floor of the clinoidal triangle, and can only be visualized after resection of the anterior clinoid process.

The C3 part of the ICA, also known as the cavernous or intracavernous segment, is located medially to the oculomotor, trochlear, ophthalmic, and abducens nerves. This segment has three named branches: the meningohypophyseal artery, the inferior cavernous sinus artery and the McConnell capsular artery. Of these, the meningohypophyseal artery (or trunk) is the largest and most constant. It arises medially from the middle third of the medial curve of the ICA and divides into three other branches, the tentorial, dorsal meningeal, and inferior hypophyseal arteries. The next artery to arise from the cavernous segment of the ICA is the inferior cavernous sinus artery (or inferolateral trunk), at the inferolateral or lateral portion of the horizontal segment of the cavernous portion of the ICA. It is important to note that, although the ophthalmic artery usually arises distal to the distal dural ring on the medial portion of the anterior wall of the ICA, it may sometimes arise within the CS, at the clinoid segment of the ICA, or even as a branch of the middle meningeal artery.

According to Rhoton, ${ }^{13}$ the cavernous portion of the ICA may be divided into five regions: the posterior vertical segment, the posterior bend, the horizontal segment, the anterior bend and the anterior vertical segment. The posterior vertical segment is the ascending segment of the ICA that begins immediately at its emergence from the foramen lacerum, and ends when the artery curves anteriorly to form the posterior bend. The intracavernous ICA then courses anteriorly, and slightly laterally, as

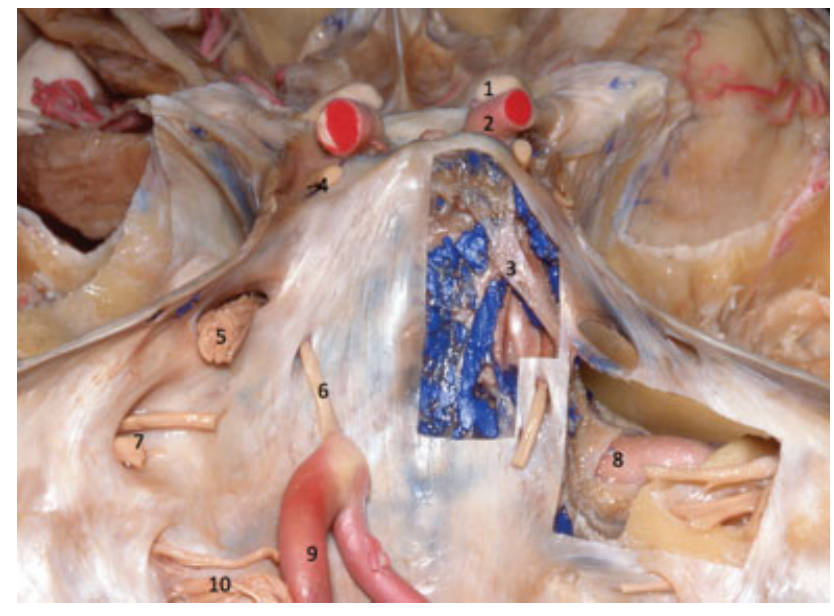

Fig. 2 Postero-superior view of the cavernous sinus: 1: Optic nerve 2: Supraclinoid segment of the ICA 3: Petrosphenoidal ligament (Grubber) 4: Trochlear nerve 5: Trigeminal nerve 6: Abducens nerve 7: Facial and Vestibulocochlear nerves entering the internal acoustic meatus 8: Petrous segment of ICA 9-vertebral artery 10: Glossopharyngeal and Vagus nerves entering the Jugular foramen. 


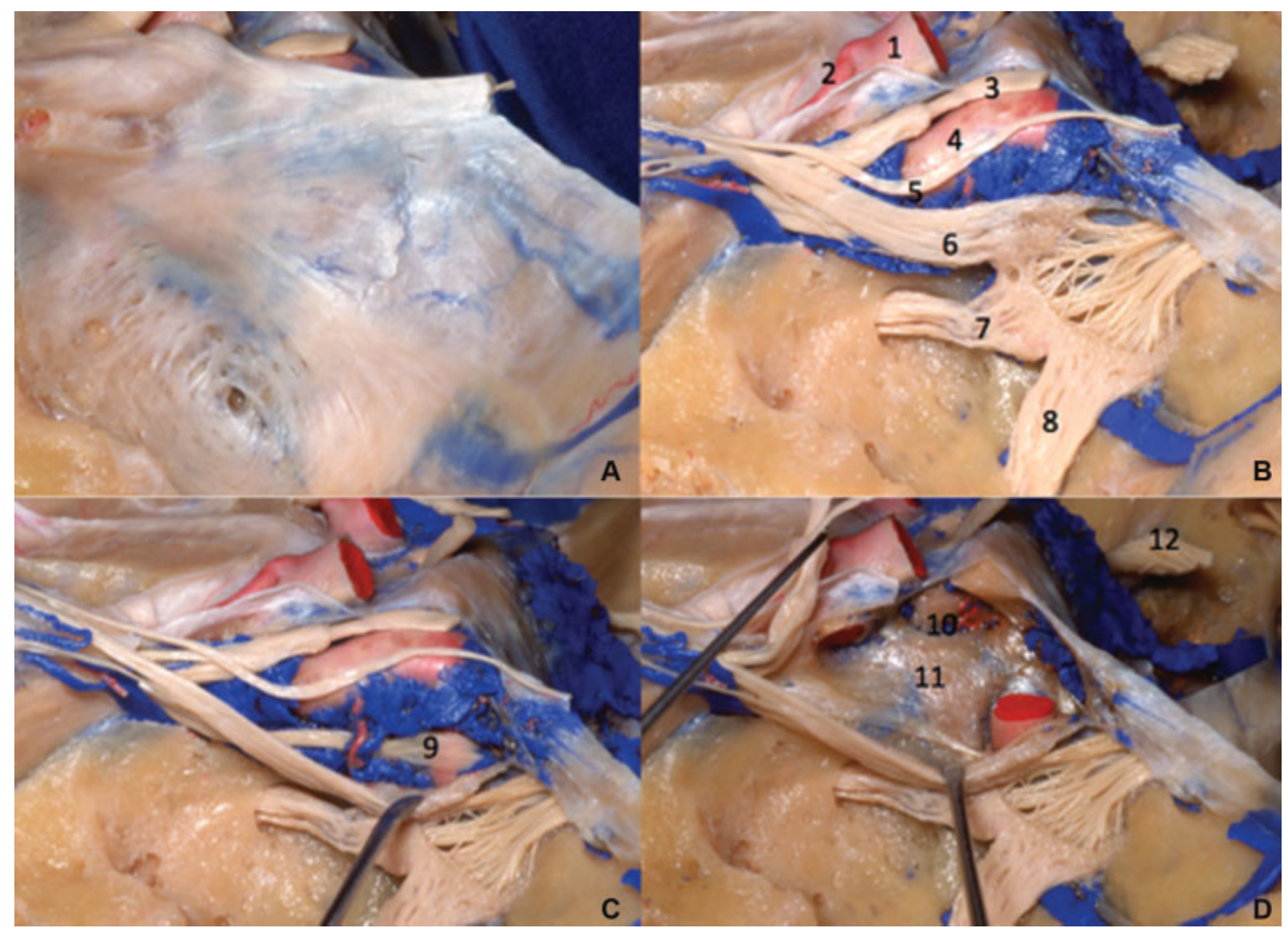

Fig. 3 Oblique view of the left cavernous sinus: A) before removal of dural layers. (B) after removal of dural layers and anterior clinoid process. 1: ICA (supraclinoidal), 2: ophthalmic artery, 3: oculomotor nerve, 4: ICA (cavernous portion), 5: trochlear nerve, 6: ophthalmic nerve (V1), 7: maxillary nerve (V2), 8: mandibular nerve (V3). C- after displacement of V1. 9: abducens nerve. (C) after removal of cavernous ICA. 10: pituitary stalk 11: medial wall of cavernous sinus. 12: contralateral trigeminal nerve.

the horizontal segment, which bends $90^{\circ}$ superomedial to the anterior clinoid process, forming the anterior bend. Finally, the ICA takes a vertical course, perforating the roof of the CS and entering the subarachnoid space; this portion of the artery is known as the anterior vertical segment (-Fig. 3 ).

The meningohypophyseal artery or trunk is present in $90 \%$ of CSs. Through the tentorial, dorsal meningeal, and inferior hypophyseal arteries, which form a trifurcation in $70 \%$ of individuals, it supplies the tentorium cerebelli, the dural covering of the basilar plexus, and the posterior pituitary, respectively. The meningohypophyseal artery may be absent or hypoplastic, in which case its branches may arise directly from the cavernous segment of the ICA.

The tentorial artery, also known as the artery of Bernasconi and Cassinari, is present in $100 \%$ of individuals and usually arises from the meningohypophyseal trunk, although it may arise directly from the cavernous segment of the ICA or from the inferior CS artery. Furthermore, when this artery is hypoplastic, an accessory tentorial artery - arising from the middle meningeal or inferior cavernous sinus artery may also be present. The tentorial artery gives off branches that supply the oculomotor and trochlear nerves, and can also give rise to branches that course toward the roof of the cavernous sinus and may join the meningeal branches of the ophthalmic artery.
The dorsal meningeal artery supplies the dura of the clival region and the posterior portion of the CS. It arises from the meningohypophyseal artery in $90 \%$ of cases and directly from the ICA, inferior hypophyseal artery, or inferior cavernous sinus artery otherwise, and may be absent in $10 \%$ of individuals. The dorsal meningeal artery courses posterior and inferomedially, crossing the posterosuperior venous space and running inferior to the petroclinoid (Gruber) ligament. At this location, the artery runs medial to the abducens nerve before it enters the basilar plexus. It ends at the dura that overlies the basilar portion of the occipital bone, where it anastomoses with its contralateral partner. In the Dorello canal, the dorsal meningeal artery divides into branches that supply the abducens nerve.

The inferior hypophyseal artery arises from the meningohypophyseal trunk in 70 to $80 \%$ of cases. In the remainder of individuals, it may arise directly from the medial surface of the horizontal segment of the ICA. After its origin, it follows an anteromedial course, crossing the venous space medial to the ICA. As it approaches the posterior floor of the sella, it bifurcates or trifurcates into superior or inferior branches, which run superiorly and inferiorly, ending at the cleft that divides the anterior and posterior lobes of the pituitary. These branches anastomose with their contralateral partners. 
The inferior cavernous sinus artery, also known as the inferolateral trunk, arises laterally from the middle portion of the horizontal segment of the cavernous ICA, $\sim 5$ to $8 \mathrm{~mm}$ distal to the source of the meningohypophyseal artery. It arises directly from the carotid in $84 \%$ of individuals and from the meningohypophyseal artery in $6 \%$ of cases. In a case series by Parkinson, ${ }^{12}$ this artery was found in $80 \%$ of the 200 CSs examined. The inferior CS artery gives off branches toward the foramen spinosum, which then anastomose with branches of the middle meningeal and accessory meningeal arteries. It is also the main provider of arterial blood supply to the trigeminal ganglion.

The McConnell capsular artery is the least constant branch of the intracavernous segment of the ICA, identified in only 25 to $30 \%$ of cases. ${ }^{14}$ However, Ferrareze Nunes found it in $70 \%{ }^{15}$

\section{Venous Relationships}

The CS has four venous spaces, which are defined concerning the cavernous portion of the ICA, namely: medial, lateral, anteroinferior, and posterosuperior. ${ }^{13}$ Both CSs communicate across the midline through the intercavernous sinuses. The afferent vessels of the CS are the superior and inferior ophthalmic veins, the sphenoparietal sinus, the superficial middle cerebral vein, and the middle meningeal veins. Its efferent vessels are the basilar plexus and the inferior and superior petrous sinuses. It may communicate laterally with the pterygoid plexus through an emissary vein or the foramen ovale. A variety of venous plexuses may extend inferiorly to the clivus, posteriorly and below the dural aspect of the inferior middle fossa and laterally. ${ }^{16}$

\section{Walls of the Cavernous Sinus}

Two dural layers form the lateral wall of the CS (inner, or endosteal, and outer, or meningeal) are attached weakly to one another. After dissection of the meningeal layer and of the middle fossa dura lateral to the CS, cranial nerves (CNs) III, IV, V1, V2, and V3, the lesser and greater superficial petrosal nerves, and the venous spaces of the CS can be identified. Within the Cavernous Sinus (CS), CNs III, IV, and V1 can be visualized through the semitransparent external portion of the inner layer. At the level of the Meckel cave, the lateral wall of the CS joins the dural lining of the base. A surgical corridor into the CS through this wall may be pursued through the triangular spaces between the oculomotor and trochlear nerve (supratrochlear triangle) or between the trochlear nerve and the upper boundary of CN V1 (infratrochlear or Parkinson triangle). The outer layer is more firmly attached around the nerves at the points of entry at their respective foramina. Separation of the outer and inner layer is therefore more technically challenging near the superior orbital fissure and the foramen ovale and rotundum. ${ }^{17-19}$ The medial wall of the SC is located on the body of the sphenoid bone and is formed by the inner portion of the endosteal layer. It is bordered anteriorly by the superior orbital fissure, posteriorly by the dorsum sellae, inferiorly by the upper margin of the maxillary nerve, and superiorly by the diaphragm sellae. A plane separates the pituitary capsule and the medial wall of the CS. The dura of the medial wall of the CS is exceedingly thin and compact and cannot be divided into layers. The medial wall of the CS has two very well-defined anatomically parts, in relationship with the pituitary gland and the carotid sulcus, respectively.

The superior wall of the CS is made up of two layers (-Fig.2), the inner of these being the thinnest. The superior wall can be divided into two triangles: the clinoidal (anterior) triangle and the oculomotor (posterior) triangle. The anterior portion of the superior wall is bounded by the optic nerve (confined within the optic canal), the medial surface of the oculomotor nerve, and the dural reflection which extends between the dural entry point of the oculomotor nerve and the optic nerve. After resection of the anterior clinoid process, the clinoid segment of the ICA emerges between the distal and proximal dural rings. The proximal ring, also known as the carotid-oculomotor membrane, constitutes the true roof of the $\mathrm{CS}^{20}$

The clinoid segment of the ICA is considered part of the CS, as there is venous blood below the carotid collar. The posterior part of the superior wall is delimited by the anterior and posterior petroclinoid and interclinoid dural folds, which form the sides of the oculomotor triangle. The oculomotor and trochlear nerves enter the posterior part of the superior wall of the CS and then course along the lateral wall (with the oculomotor nerve above the trochlear) to penetrate the superior orbital fissure. ${ }^{21}$

We recognize the boundaries of the posterior wall as those defined by Rhoton ${ }^{7}$ : the posterior petroclinoid dural fold (superior), the dura of the medial border of the trigeminal porus (lateral), the upper boundary of the petroclival fissure (inferior) and the lateral border of the dorsum sellae (medial). The abducens nerve enters the CS through the Dorello canal, which is bounded superiorly by the petrosphenoidal (Gruber) ligament, a fibrous bundle that extends from the petrous apex to the superior clivus. ${ }^{23}$

\section{Triangles of the Cavernous Sinus}

Parkinson described a triangle on the lateral wall of the cavernous sinus through which the intracavernous portion of the ICA could be exposed. Since his pioneering studies, several important triangular relationships formed by the convergence and divergence of cranial nerves have been described in the CS, in the middle cranial fossa, and in the paraclival region. ${ }^{22,24-26}$

Four triangular areas have been identified in the CS, four in the middle fossa, and two in the paraclival region. The triangles of the cavernous sinus are formed by the optic, oculomotor, trochlear, and ophthalmic nerves as they converge to the optic canal and the superior orbital fissure. The middle fossa triangles are formed by the divisions of the trigeminal nerve, diverging from the trigeminal ganglion to their respective foramina. The paraclival triangles are delimited by bony, neural, and vascular structures (-Figs. 2 and 4). A summarized description of all 10 triangles limits and locations can be seen in - Table 1.

Some authors still disagree on the nomenclature applied to some of these triangular spaces. The adoption of different nomenclature can lead to confusion when authors give the same name to distinct triangles. Describing each triangle in terms of the structures that form its boundaries is a more 
Table 1 Skull base triangles, limits location and endoscopic view

\begin{tabular}{|c|c|c|c|}
\hline Triangle & Limits & Location & Endoscopic View \\
\hline Clinoidal & $\begin{array}{l}\text { II CN } \\
\text { III CN } \\
\text { Dura }\end{array}$ & Superior wall of CS & Small portion \\
\hline Oculomotor & $\begin{array}{l}\text { Ant. Petroclinoidal fold } \\
\text { Post. Petroclinoidal fold } \\
\text { Interclinoidal fold }\end{array}$ & Superior wall of CS & Not identifiable \\
\hline Supratrochlear & $\begin{array}{l}\text { III CN } \\
\text { IV CN } \\
\text { Dural incisure }\end{array}$ & Lateral wall of CS & Anterior extremity \\
\hline Infratrochlear (Parkinson) & $\begin{array}{l}\text { IV CN } \\
\text { V1 } \\
\text { Dural incisure }\end{array}$ & Lateral wall of CS & Not adequately identifiable \\
\hline Anteromedial & $\begin{array}{l}\text { V1 } \\
\text { V2 } \\
\text { Dura V1-V2 }\end{array}$ & Middle Fossa & Readily Identifiable \\
\hline Anterolateral & $\begin{array}{l}\text { V2V3 } \\
\text { Dura V2-V3 }\end{array}$ & Middle Fossa & Partially viewed \\
\hline Posterolateral (Glasscock) & $\begin{array}{l}\text { V3 } \\
\text { GPN } \\
\text { line from FS to } A E\end{array}$ & Middle Fossa & None* \\
\hline Posteromedial (Kawase) & $\begin{array}{l}\text { TG } \\
\text { GPN } \\
\text { Petrous border of SPS }\end{array}$ & Middle Fossa & None* \\
\hline Inferomedial & $\begin{array}{l}\text { PCP-VI CN entrance dura } \\
\text { line VI CN-IV CN (entrances) } \\
\text { PA }\end{array}$ & Paraclival & None* \\
\hline Inferolateral & $\begin{array}{l}\text { line VI CN-IV CN (entrances) } \\
\text { Dura VI CN entrance-SPS } \\
\text { PA }\end{array}$ & Paraclival & None* \\
\hline
\end{tabular}

Abreviations: AE, arcuate eminence; CS, cavernous sinus; FS, foramen spinosum; GPN, greater petrosal nerve; II CN, optic nerve; III CN, oculomotor nerve; IV CN, trochlear nerve; PA, petrous apex; PCP, posterior clinoid process; SPS, superior petrosal sinus; TG, trigeminal ganglion; V1, ophthalmic division of trigeminal nerve; V2, maxillar division of Trigeminal nerve; V3, mandibular division of trigeminal Nerve; VI, abducens nerve.

${ }^{*}$ Although these triangles were not viewed through Endonasal Transphenoidal approach, they might be visualized through lateral extended endonasal approach.

time-consuming method, but provides a precise, uniform means of exchanging information on an anatomical region that is challenging enough in and of itself. For practical

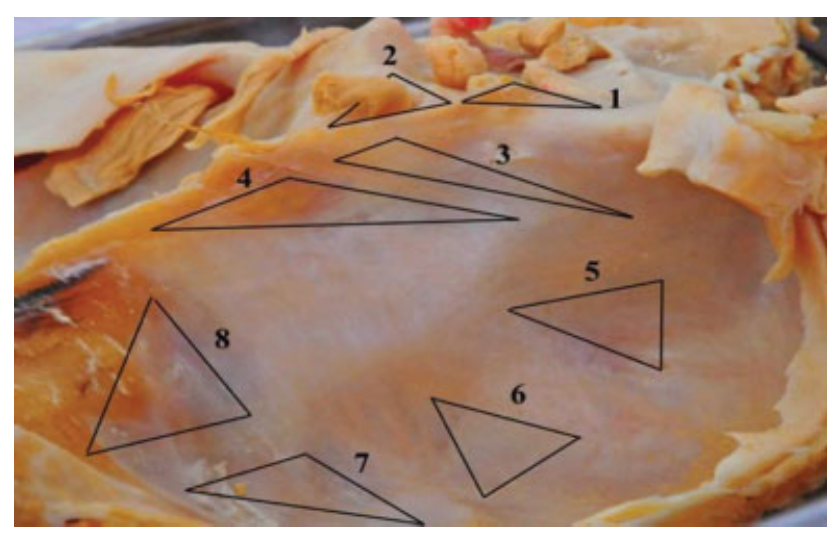

Fig. 4 Right cavernous sinus lateral wall with triangular spaces delimitations: 1: Clinoidal triangle, 2: Oculomotor triangle, 3: Supratroclear triangle, 4: Infratroclear triangle, 5: Anteromedial triangle, 6: Anterolateral triangle, 7: Posterolateral triangle, 8: Posteromedial triangle. purposes, the present study uses the nomenclature adopted by. Dolenc et al. ${ }^{27-29}$

These triangular spaces constitute natural anatomical corridors through which lesions located within the CS can be approached and resected. However, in some pathological processes, particularly tumors, these geometric spaces may be distorted and atypically shaped. In these cases, the choice of approach and intraoperative decision-making are best established through one or more approaches that use one of the four walls of the CS SC (lateral, medial, superior, or inferior) as a landmark, rather than based on the static anatomy of the surgical triangles. ${ }^{2,30-32}$

\section{Clinoidal Triangle}

The clinoidal triangle is bounded medially by the optic nerve, laterally by the oculomotor nerve as it passes through the superior orbital fissure, and by the dura that extends between the dural entry site of the ICA as it enters the supraclinoid region (-Fig. 3). The dural ring is medially continuous with the dura of the diaphragm sellae. Another membrane, the carotid-oculomotor membrane, extends over 
the lateral portion of the carotid artery, through the interval between the carotid artery and the oculomotor nerve, medially from the oculomotor nerve to the posterior clinoid process, and attaches superiorly to the interclinoid ligament. The anterior portion of this membrane separates the cavernous sinus and the clinoid segment of the ICA. The space between both membranes is known as the clinoidal space. This membrane extends inferiorly to the lateral part of the cavernous sinus, where it is continuous with the inner reticular layer of the lateral wall of the sinus.

\section{Oculomotor Triangle}

The oculomotor nerve triangle corresponds to the entry site of this nerve in the posterosuperior portion of the roof of the cavernous sinus. The triangle is formed by the anterior petroclinoid fold, the posterior petroclinoid fold, and the interclinoid fold, the dural folds that cover the anterior and posterior clinoid processes and the petrous apex. Through this triangle, surgeons may expose and resect the posterior clinoid process to obtain access to the interpeduncular and pontine cisterns, as well as to the basilar artery, when its bifurcation is situated below the posterior clinoid process (-Fig. 3).

\section{Supratrochlear Triangle}

The margins of the supratrochlear triangle are the oculomotor nerve (medial), the trochlear nerve (lateral), and the dura stretching between the points of entrance of these nerves. Structures that have been identified in this triangle include the horizontal segment of the cavernous portion of the ICA, the abducens nerve, the inferior CS artery, and the meningohypophyseal artery. The inferior CS artery arises from the lateral portion of the horizontal segment of the ICA (-Fig. 3).

\section{Infratrochlear (Parkinson) Triangle}

The Parkinson triangle is bounded medially by the trochlear nerve, laterally by the ophthalmic branch of the trigeminal nerve, and posteriorly by the dura between these nerves. The vertical segment and medial loop of the cavernous ICA have been identified in this triangle, as has the origin of the meningohypophyseal trunk, which is the most proximal branch to arise below the level of the dorsum sellae, near the apex of the posterior loop. The meningohypophyseal trunk is divided into three branches: the tentorial artery (artery of Bernasconi and Cassinari), which courses toward the tentorium; the inferior hypophyseal artery, which follows a medial course and supplies the posterior pituitary; and the dorsal meningeal artery, which supplies the dura of the clivus and the abducens nerve ( - Fig. 3 ).

\section{Anteromedial Triangle}

The anterolateral triangle is delimited anteriorly by an imaginary line of dura running between the ophthalmic and maxillary nerves, medially by the ophthalmic nerve, and laterally by the maxillary nerve. A slight retraction of the ophthalmic nerve enables visualization of the horizontal distal portion of the cavernous segment of the ICA and of the abducens nerve. The inferior CS artery is situated within this triangle, running between the abducens nerve and the ophthalmic nerve toward the lateral wall of the CS. Opening of the floor of this space provides access to the sphenoidal sinus. A more anterior approach allows entry into the pterygopalatine fossa (-Fig. 4).

\section{Anterolateral Triangle}

The boundaries of the anterolateral triangle are the maxillary nerve anteromedially, the mandibular nerve posteriorly, and, anterolaterally, the dura between the two nerves, over the lateral wall of the middle fossa. Partial visualization of the sphenoidal sinus is possible through this triangle. Drilling the bone of the middle fossa laterally provides additional access for expanded lateral exposure. A more anterior approach provides entry into the infratemporal fossa (-Fig. 3).

\section{Posterolateral (Glasscock) Triangle}

The posterolateral, or Glasscock, triangle is bounded laterally by a line running from the foramen spinosum to the arcuate eminence, medially by the greater petrosal nerve, and at its base by the mandibular nerve. Careful drilling of this triangle enables exposure of the horizontal portion of the ICA (-Fig. 3).

Exposure of the tensor tympani muscle and of the horizontal portion of the ICA may be achieved through this triangle, by dividing the greater petrosal nerve and drilling anterior and adjacent to its groove and medially to its hiatus. Particular care must be taken to avoid injury to the cochlea, which is located anteromedially to the geniculate ganglion and facial canal and immediately posterior to the posterior loop of the ICA.

\section{Posteromedial (Kawase) Triangle}

The posteromedial triangle is bordered anteriorly by the posterior margin of the trigeminal ganglion, laterally by the greater petrosal nerve, and medially by the petrous border with the superior petrosal sinus. Drilling out the petrous part of the temporal bone exposes the dura of the petrosal surface of the posterior fossa, providing access to the anterior clival region. The field thus exposed is bounded by the superior and inferior petrosal sinuses medially, by the internal acoustic meatus and cochlea posteriorly, and by the ICA laterally (-Fig. 3).

\section{Inferomedial Paraclival Triangle}

The inferomedial paraclival triangle is delimited by a line on the dural surface extending from the posterior clinoid process to the entrance site of the abducens nerve at the Dorello canal, by a line extending between the Dorello canal and the dural entrance point of the trochlear nerve on the tentorium (laterally), and the petrous apex (forming its base). After peeling back the dura, the basilar venous plexus, the dorsal meningeal artery, the petroclinoid ligament, the posterior genu of the cavernous segment of the ICA, and the origin of the meningohypophyseal artery are all visible within this triangle (-Fig. 2 ). 


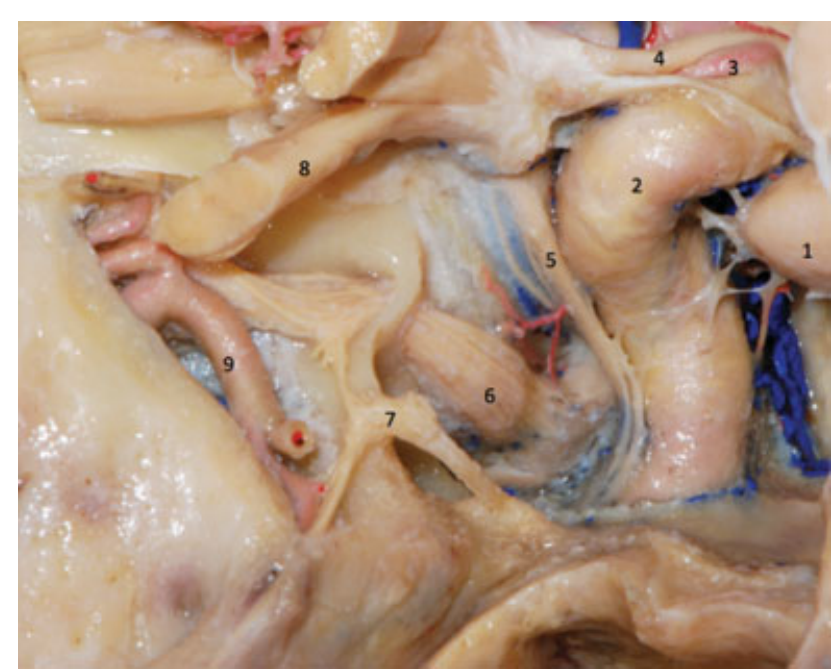

Fig. 5 Extended endoscopic view of the right cavernous sinus. 1: Pituitary gland, 2: ICA - cavernous segment, 3: Ophtalmic artery, 4: Optic nerve, 5: VI nerve, 6: V2, 7: Pteryopalatine Ganglion, 8: Inferior Rectus Muscle, 9: Maxillary Artery.

\section{Inferolateral Paraclival Triangle}

The boundaries of this triangle are a line extending between the dural entrance point of the trochlear nerve and the Dorello canal (medial), the dura between the Dorello canal and the point where the petrosal vein enters the superior petrosal sinus (lateral), and the petrous apex (base) (-Fig. 2).

\section{Endoscopic Anatomy}

The extended transsphenoidal endoscopic approach provides an excellent, though incomplete, view of the structures of the CS. The anatomical architecture of the area, with structures stratified into several planes, allows at least partial visualization of all elements, except for the ICA, which is uniformly well-visualized and, due to its unique importance, serves as an anatomical barrier dividing the anterior and posterior surgical corridors (-Figs. 5 and $\mathbf{6}$ ).

The clinoidal triangle was observed in only a comparatively small portion of specimens when viewed endoscopically. The optic strut, which forms the middle part of this triangle, can be identified endoscopically as corresponding to the opticocarotid recess, which can only be visualized under endoscopy if the sphenoid is pneumatized.

The supratrochlear triangle can only be identified by its anterior extremity, where the oculomotor and trochlear nerves reach the superior orbital fissure. This space can only be identified after careful medial displacement of the ICA.

Endoscopic identification of the Parkinson triangle is challenging, due to the difficulty of exposing the course of the trochlear nerve. The oculomotor triangle could not be adequately identified through the endoscopic approach, even after medial displacement of the ICA.

The anteromedial triangle, on the other hand, was readily identifiable. Its apex, which corresponds to the angle formed by the ophthalmic and maxillary branches of the trigeminal nerve, could be identified after isolation and medial retraction of the ascending vertical segment of the ICA.

Regarding the anterolateral triangle, although the maxillary nerve is easily identified endoscopically, the mandibular nerve can only be visualized proximal to the trigeminal ganglion.

The Glasscock and Kawase triangles, as well as the paraclival triangles, are not amenable to endoscopic visualization via sphenoid sinus as we observed in our results, as they have

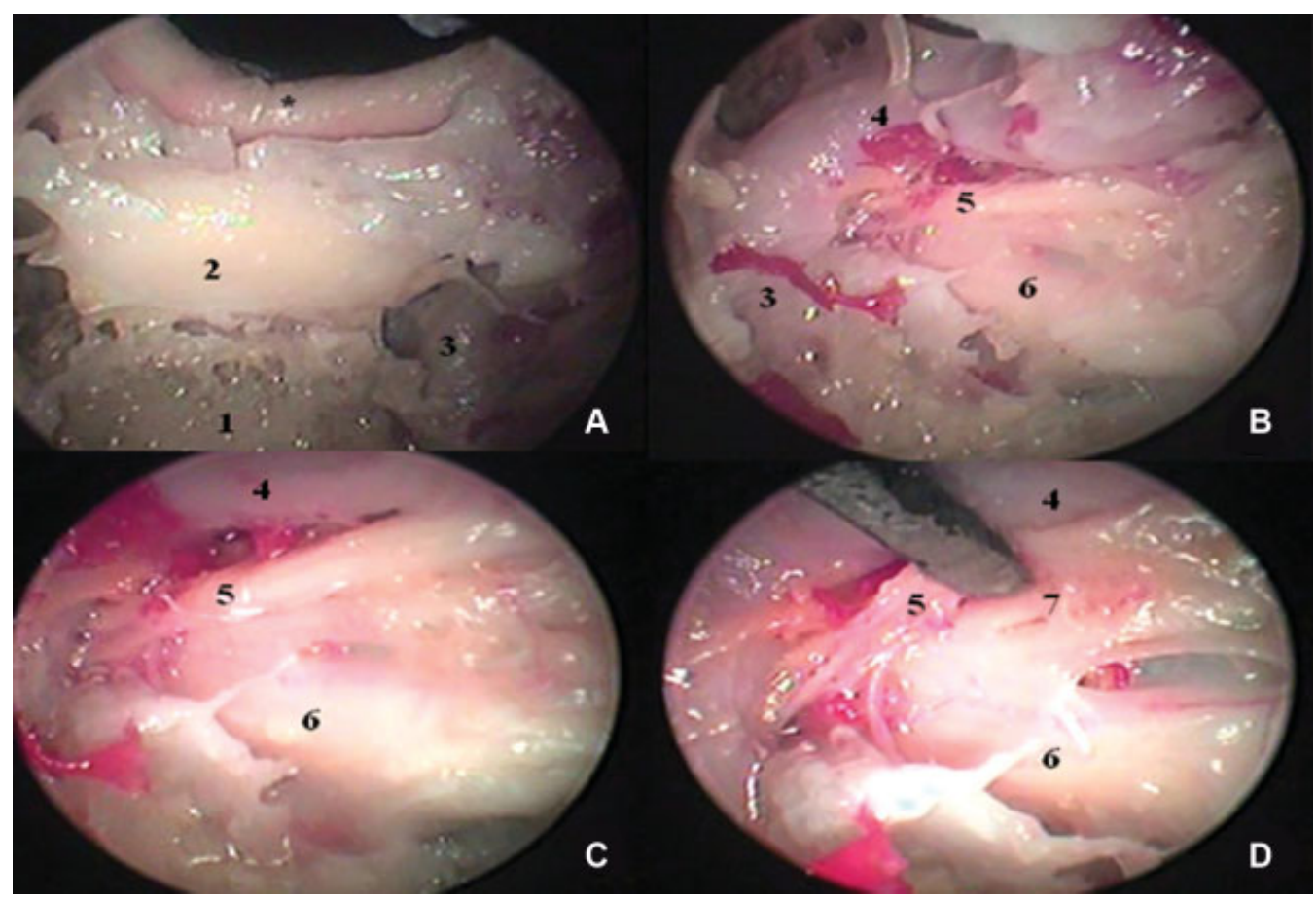

Fig. 6 Endonasal endoscopic view of the parasellar structures through the medial wall of the left cavernous sinus, after ressection of the bony wall of the sphenoid sinus. 1: Superior clivus, 2: Pituitary gland, 3: Internal carotid artery (intra petrosal portion), 4: Internal carotid artery (intra cavernous portion), 5: Abducens nerve, 6: Trigeminal nerve, 7: Oculomotor nerve: ${ }^{*}$ Optic chiasm. 


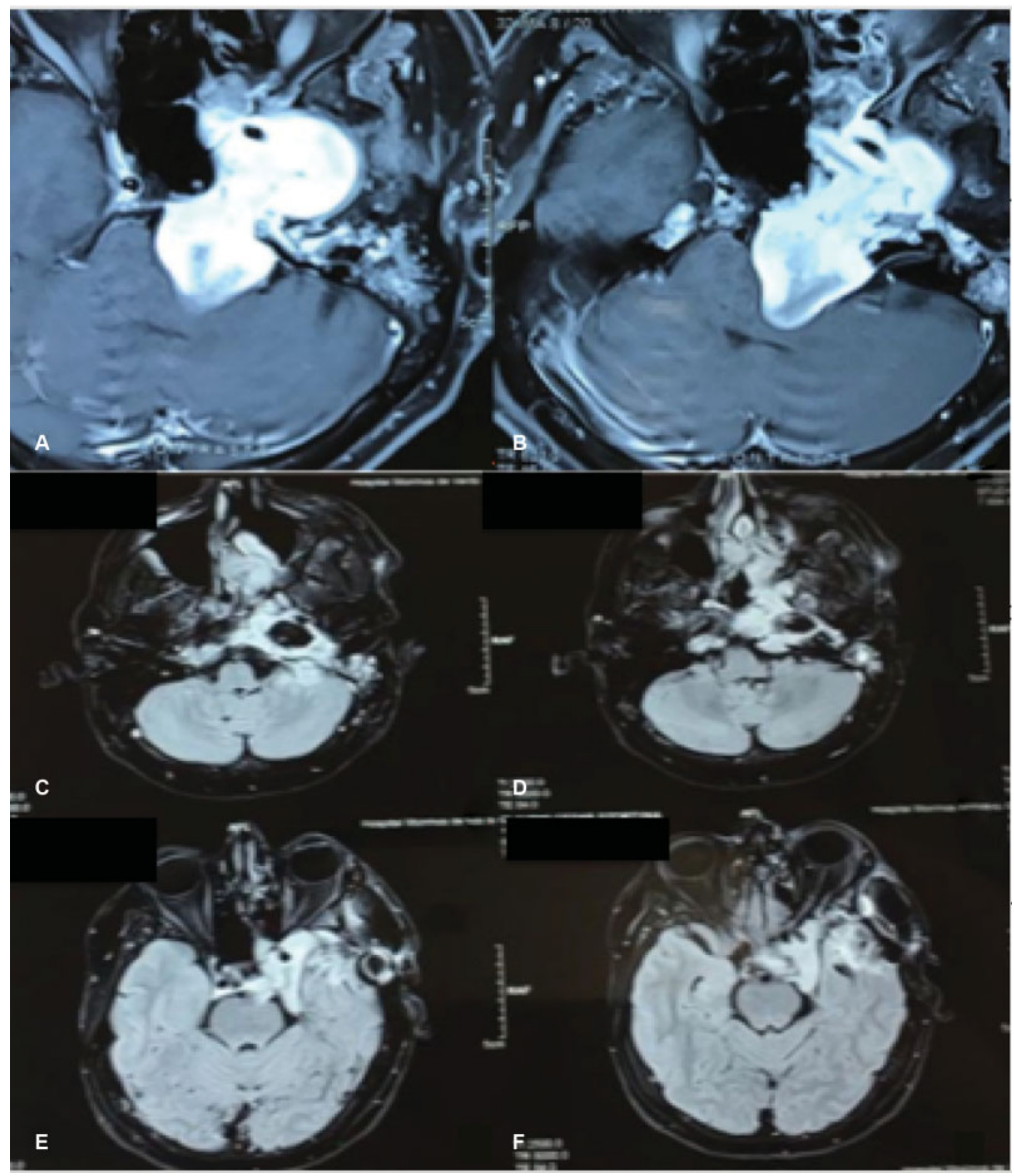

Fig. 7 Illustrative case showing a cavernous sinus chondrosarcoma with extension in the posterior fossa, sphenoid sinus, pterygopalatine fossa and infratemporal fossa. The patient had VI nerve paresis which improved 7 months after surgery. In the first surgery, a cranio-orbito-zygomatic approach with middle fossa peeling was performed and the middle and posterior fossa part of the tumor were removed extradurally (C-F).

no anatomical relationship with the sphenoidal sinus. On the other hand, lateral extended endonasal endoscopy can reach these areas.

The endoscopic approach provides access to two surgical corridors, one medial to the cavernous portion of the ICA and one lateral to it.
The C-shaped medial corridor is bounded anteriorly by the ICA and posteriorly by the dorsum sellae and posterior petroclinoid fold. Access to this corridor requires the use of an endonasal approach contralateral to the cavernous sinus of interest, as well as slight medial displacement of the pituitary. The medial corridor is narrow, and appears 
magnified as the endoscope advances. When the field of view is sufficiently magnified, the operator is able to identify the abducens nerve, as it courses lateral to the ICA, and the proximal segment of the maxillary nerve, on the lateral wall of the CS.

The lateral corridor is bounded posteriorly by the cavernous portion of the ICA, inferiorly by the vidian nerve, and anteriorly by the medial pterygoid process. After identification of the nerves on the lateral wall of the CS, viewed from an inferior perspective, the superior triangular area (between the oculomotor and abducens nerves and the ICA), the superior quadrangular area (between the abducens and maxillary nerves and the lateral wall of the sphenoidal sinus), and the inferior quadrangular area (an extracavernous region present when the sphenoidal sinus is extensively pneumatized laterally, situated between the maxillary and vidian nerves) can be delimited.

We show illustrative cases in -Figs. 7, 8 and $\mathbf{9}$.

\section{Discussion}

Endoscopic procedures are more challenging than conventional open surgery, due to the lack of three-dimensional vision, the optical distortion of the images obtained, and the constrained working area. ${ }^{8,33,34}$

The evolution of optical equipment and operative techniques through the $20^{\text {th }}$ century made a variety of increasingly improved approaches and techniques available to all surgical

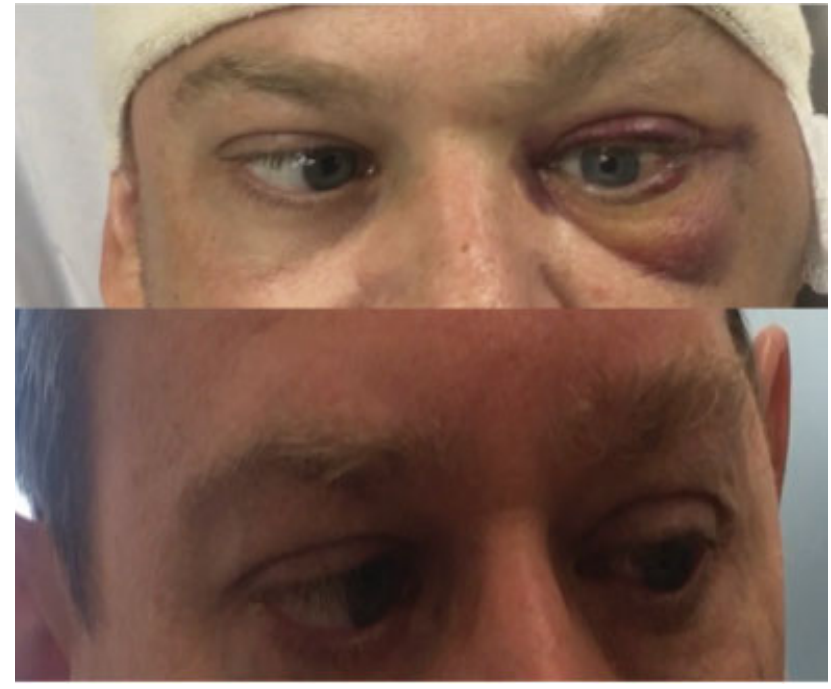

Fig. 9 The superior view shows a VI nerve palsy after the first surgery which improved later (inferior picture).

specialties. In neurosurgery, the introduction of the operating microscope was an enormous stride; by bringing microsurgical dissection techniques to the surgical practice, the microscope vastly expanded the capacity of the neurosurgeon to reach deep intracranial structures with a keener knowledge of their anatomy. The optical instrument, magnification device, and focused light source became part of a single instrument, making the aforementioned technical

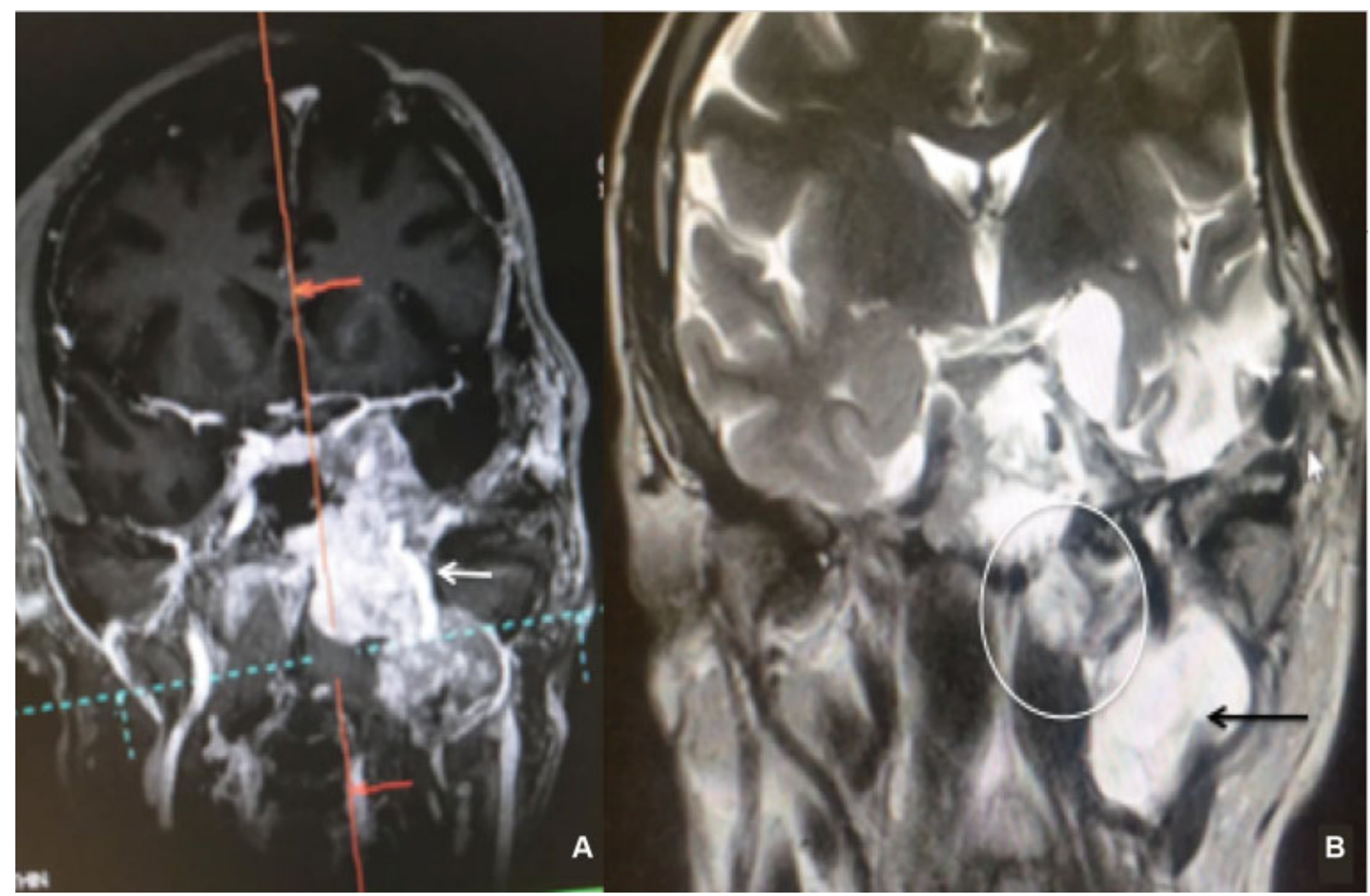

Fig. 8 The second surgery was performed 1 year later and was an extended endoscopic endonasal approach (A). The part of the tumor medial to the intracavernous and intrapetrous carotid artery was removed near totally (B). The circle in B shows the resection after the second surgery (endonasal endoscopic). A pretemporal infratemporal fossa approach is scheduled to resect the part of the tumor lateral to the cervical internal carotid artery (arrow in B). After this third surgery, irradiation of the small fragment of the tumor attached to the internal carotid artery will be performed. 
advances possible. Endoscopy is one further step of this evolution, in the sense that optical instruments can now be inserted directly into the body of the patient. The development of optical devices with attached light sources has enabled surgical exploration and manipulation of the cavities of the body through minimally invasive orifices. Endoscopic techniques have also evolved, as surgeons have become more familiar with the method and gained greater expertise in the manipulation of instruments within the constrained working space and in the prevention and management of complications. ${ }^{35}$

One frequent complication of endonasal endoscopic surgery is the high rate of cerebrospinal fluid (CSF) leak. This complication has been overcome with the advent of the pedicled nasoseptal flap technique for reconstruction of bony defects created during the use of the transsphenoidal approach. $^{36}$

Another feared complication, widely regarded as the most severe complication of endoscopic surgery of the CS, is bleeding. ${ }^{37}$ Venous bleeding should be managed carefully, with patience and adequate use of hemostatic agents. In the early steps of resection of any lesion situated in the CS, the sinus is collapsed due to the mass effect of the injury, and major bleeding is rarely observed. After partial complete resection of the lesion, bleeding usually becomes brisk due to the filling of the previously collapsed vasculature of the CS. Achieving hemostasis in this situation requires calm and expertise on the part of the operator, and poses typically no major risk to the patient.

Arterial injury is the most fearsome complication of this type of approach. Accidental laceration of the ICA will force the surgeon to terminate the procedure, apply gentle local compression on the injury and tamponade the site of bleeding with hemostatic agents. In case of a formation of a pseudoaneurysm, surgical management has to be done by bypass surgery and endovascular closure of the ICA at the C3 segment.

In spite of the improvement of endoscopic transnasal approaches and strategies, the visualization of the CS remains poor. Subsequently, extended approaches have been proposed, such as ethmoid-pterygo-sphenoidal approach (EPSA), clival approach and supradiaphragmatic approach, which could provide a better view to the lateral part of the CS.

The EPSA includes a medial approach that is medial to the internal carotid artery and lateral that is lateral to the internal carotid artery. It is believed that EPSA-medial is able to expose the medial compartment and the posterosuperior compartment and part of the posteroinferior compartment. The ethmoid-pterygoid-sphenoid lateral approach to the CS is adequate to visualize the anteroinferior compartment, the lateral CS and the CNs in the lateral wall.

\section{Conclusion}

Comparisons between traditional microsurgical anatomy and endoscopic anatomy are significant, as they provide an analogical mean of applying natural advancements in surgical knowledge and operative techniques.
Prior familiarity with the gross and microsurgical anatomy of any region of interest is required if surgery is to evolve into less invasive techniques that constrain the field of view and working area of the surgeon.

Cavernous sinus endoscopy is a minimally invasive technique that provides access to the anatomical structures present within this cavity. Although it does not provide the surgeon with as broad a field of view as that made possible by transcranial techniques, the surgical corridors described in the present work may constitute an excellent alternative approach for the resection of neoplastic lesions located within the CS.

\section{Conflict of Interests}

The authors have no conflict of interests to declare.

\section{References}

1 Chen L, Huang X, Mao Y, Zhou L. Reconsideration of cavernous sinus surgeries. Neurosurgery 2014;61(Suppl 1):130-134. Doi: 10.1227/NEU.0000000000000402

2 Al-Mefty O, Smith RR. Surgery of tumors invading the cavernous sinus. Surg Neurol 1988;30(05):370-381. Doi: 10.1016/00903019(88)90200-5

3 DeMonte F, Smith HK, al-Mefty O. Outcome of aggressive removal of cavernous sinus meningiomas. J Neurosurg 1994;81(02): 245-251. Doi: 10.3171/jns.1994.81.2.0245

4 Eisenberg MB, Al-Mefty O, DeMonte F, Burson GT. Benign nonmeningeal tumors of the cavernous sinus. Neurosurgery 1999;44 (05):949-954, discussion 954-955. Doi: 10.1097/00006123199905000-00008

5 Cohen-Cohen S, Gardner PA, Alves-Belo JT, et al. The medial wall of the cavernous sinus. Part 2: Selective medial wall resection in 50 pituitary adenoma patients. J Neurosurg 2018;131(01):131-140. Doi: $10.3171 / 2018.5$.JNS18595

6 Micko A, Oberndorfer J, Weninger WJ, et al. Challenging Knosp high-grade pituitary adenomas. J Neurosurg 2019;31:1-8. Doi: 10.3171/2019.3.JNS19367

7 Rhoton AL Jr, Inoue T. Microsurgical approach to the cavernous sinus. In: Clinical Neurosurgery. Baltimore: The Willian \& Wilkins Company; 1989:391-439

8 Romero FR, Ramires D, Cristiano LC, Silva MP, Vieira RB. Endoscopic and microsurgical approaches to the cavernous sinus anatomical review. Arq Bras Neurocir 2017;36(03):160-166

9 Isolan GR, Rowe R, Al-Mefty O. Microanatomy and surgical approaches to the infratemporal fossa: an anaglyphic threedimensional stereoscopic printing study. Skull Base 2007;17 (05):285-302. Doi: 10.1055/s-2007-985193

10 Yasuda A, Campero A, Martins C, Rhoton AL Jr, de Oliveira E, Ribas GC. Microsurgical anatomy and approaches to the cavernous sinus. Neurosurgery 2005;56(1, Suppl)4-27, discussion 4-27. Doi: 10.1227/01.NEU.0000144208.42171.02

11 Gibo H, Lenkey C, Rhoton AL Jr. Microsurgical anatomy of the supraclinoid portion of the internal carotid artery. J Neurosurg 1981;55(04):560-574. Doi: 10.3171/jns.1981.55.4.0560

12 Parkinson D. A surgical approach to the cavernous portion of the carotid artery. Anatomical studies and case report. J Neurosurg 1965;23(05):474-483. Doi: 10.3171/jns.1965.23.5.0474

13 Rhoton AL Jr. The supratentorial cranial space: Microsurgical anatomy and surgical approaches. Neurosurg. 2002;21(01): 375-410. Doi: 10.1097/00006123-200210001-00001

14 Parkinson D. Collateral circulation of cavernous carotid artery: Anatomy. Can J Surg 1964;7:251-268. Doi: 10.3171/jns.1965.23.5.0474

15 Ferrareze Nunes C, Beer-Furlan A, Doglietto F, Carrau RL, Prevedello DM. The McConnell's Capsular Arteries and Their Relevance 
in Endoscopic Endonasal Approach to the Sellar Region. Oper Neurosurg (Hagerstown) 2018;14(02):171-177. Doi: 10.1093/ ons/opx107

16 Harris FS, Rhoton AL. Anatomy of the cavernous sinus. A microsurgical study. J Neurosurg 1976;45(02):169-180. Doi: 10.3171/ jns.1976.45.2.0169

17 Campero A, Campero AA, Martins C, Yasuda A, Rhoton AL Jr. Surgical anatomy of the dural walls of the cavernous sinus. J Clin Neurosci 2010;17(06):746-750. Doi: 10.1016/j.jocn.2009.10.015

18 Umansky F, Nathan $\mathrm{H}$. The lateral wall of the cavernous sinus. With special reference to the nerves related to it. J Neurosurg 1982;56(02):228-234. Doi: 10.3171/jns.1982.56.2.0228

19 Kobayashi M, Yoshida K, Kawase T. Inter-dural approach to parasellar tumors. Acta Neurochir (Wien) 2010;152(02):279-284, discussion 284-285. Doi: 10.1007/s00701-009-0515-y

20 Umansky F, Valarezo A, Elidan J. The superior wall of the cavernous sinus: a microanatomical study. J Neurosurg 1994;81(06): 914-920. Doi: 10.3171/jns.1994.81.6.0914

21 Tedeschi H, de Oliveira EP, Wen HT, Rhoton ALJr. Perspectives on the approaches to lesions in and around the cavernous sinus. Oper Tech Neurosurg. 2001;4(02):82-107. Doi: 10.1053/otns.2001.25568

22 Isolan GR, Krayenbühl N, de Oliveira E, Al-Mefty O. Microsurgical anatomy of the cavernous sinus: Measurements of the triangles in and around it. Skull Base 2007;17(06):357-367. Doi: 10.1055/s2007-985194

23 Ziyal IM, Salas E, Wright DC, Sekhar LN. The petrolingual ligament: the anatomy and surgical exposure of the posterolateral landmark of the cavernous sinus. Acta Neurochir (Wien) 1998;140(03):201-204, discussion 204-205. Doi: 10.1007/s007010050086

24 Miyazaki Y, Yamamoto I, Shinozuka S, Sato O. Microsurgical anatomy of the cavernous sinus. Neurol Med Chir (Tokyo) 1994; 34(03):150-163. Doi: 10.2176/nmc.34.150

25 Parkinson D. Transcavernous repair of carotid cavernous fistula. Case report. J Neurosurg 1967;26(04):420-424. Doi: 10.3171/jns.1967. 26.4.0420

26 Watanabe A, Nagaseki Y, Ohkubo S, et al. Anatomical variations of the ten triangles around the cavernous sinus. Clin Anat 2003;16 (01):9-14. Doi: 10.1002/ca.10072
27 Dolenc VV. A combined epi- and subdural direct approach to carotid-ophthalmic artery aneurysms. J Neurosurg 1985;62(05): 667-672. Doi: 10.3171/jns.1985.62.5.0667

28 Dolenc VV, Skrap M, Sustersic J, Skrbec M, Morina A. A transcavernous-transsellar approach to the basilar tip aneurysms. Br J Neurosurg 1987;1(02):251-259. Doi: 10.3109/02688698709035309

29 Dolenc VV. Approaches to and techniques of surgery within the cavernous sinus. In: Torrens $\mathrm{M}, \mathrm{Al}-$ Mefty $\mathrm{O}$, Kobayashi S, eds. Operative Skull Base Surgery. New York: Churchill Livingstone; 1997:207-236

30 Inoue T, Rhoton AL Jr, Theele D, Barry ME. Surgical approaches to the cavernous sinus: a microsurgical study. Neurosurgery 1990; 26(06):903-932. Doi: 10.1097/00006123-199006000-00001

31 Sekhar LN, Møller AR. Operative management of tumors involving the cavernous sinus. J Neurosurg 1986;64(06):879-889. Doi: $10.3171 /$ jns.1986.64.6.0879

32 Sekhar LN, Wright DC. Tumors involving the cavernous sinus. In: Sekhar LN, de Oliveira E, eds. Cranial microsurgery approaches and techiniques. New York: Thieme; 1999

33 Cavallo LM, Cappabianca P, Galzio R, Iaconetta G, de Divitiis E, Tschabitscher M. Endoscopic transnasal approach to the cavernous sinus versus transcranial route: anatomic study. Neurosurgery 2005;56(2, Suppl)379-389, discussion 379-389. Doi: 10.1227/01.neu.0000156548.30011.d4

34 Jho HD, Carrau RL. Endoscopic endonasal transsphenoidal surgery: experience with 50 patients. J Neurosurg 1997;87(01): 44-51. Doi: 10.3171/jns.1997.87.1.0044

35 Alfieri A, Jho HD. Endoscopic endonasal cavernous sinus surgery: an anatomic study. Neurosurgery 2001;48(04):827-836, discussion 836-837

36 Ceylan S, Koc K, Anik I. Endoscopic endonasal transsphenoidal approach for pituitary adenomas invading the cavernous sinus. J Neurosurg 2010;112(01):99-107. Doi: 10.3171/2009.4.JNS09182

37 Fukushima T. Direct operative approach to the vascular lesions in the cavernous sinus: Summary of 27 cases. Mt. Fuji Workshop Cerebrovasc. Dis. 1988;(06):169-189. DOI: 10.3171/2009.4. JNS09182 